\title{
NOTAS SOBRE O PROCESSO DE TRABALHO E SUA DUPLA SUBSUNÇÃO NO CAPITAL
}

Notes on the labour process and its double subsumption under capital

Édil Guedes *

Resumo: Neste artigo, após considerarmos a importância do trabalho na modernidade e, particularmente, no pensamento de Karl Marx, examinaremos a exposição marxiana do processo de trabalho em sua estrutura geral, para em seguida nos voltarmos à compreensão do que Marx chamou de subsunção formal e real do trabalho no capital, avaliando alguns de seus sentidos, implicações e desdobramentos mais importantes.

Palavras-chave: Marx. Trabalho. Capital. Subsunção. Alienação. Fetichismo.

Abstract: In this article, after considering the importance of work in modernity, and particularly in Karl Marx's thought, we will examine the Marxian exposition of the labor process in its general structure, and then seek to understand what Marx called formal and real subsumption of labor under capital, assessing some of its most important meanings, implications and developments.

Keywords: Marx. Work. Capital. Subsumption. Alienation. Fetishism.

* Doutor em Filosofia pela UFMG. Professor do PPG em Filosofia da FAJE e do ICEG-PUC Minas. Artigo recebido em 02/12/2019 e aprovado para publicação em 05/12/2019. 


\section{Introdução: a questão do trabalho na modernidade e} em $\operatorname{Marx}{ }^{1}$

$\mathrm{N}$ ão nos parece exagerado afirmar, ainda que sua demonstração exigisse outro espaço e uma série de cuidados adicionais, que ao pensamento antigo é completamente estranha a concepção do trabalho prevalecente na vida moderna, bem como a sua relevância ético-política. ${ }^{2}$

É difícil dissentir de Migeotte, quando este assevera que "em suas formas concretas, o trabalho é uma realidade tão antiga quanto o mundo: o homem sempre ganhou o pão com o suor do seu rosto". ${ }^{3}$ Mas será igualmente justa a sua avaliação de que, "na ordem da representação, ele [o trabalho] tem uma longa história". ${ }^{4}$ Com efeito, Paul Ricoeur é certeiro ao afirmar que "a descoberta ou a redescoberta do homem como trabalhador é um dos grandes acontecimentos do pensamento contemporâneo". ${ }^{5}$ Eric Weil ainda nos permite acrescentar que, se por um lado toda sociedade constitui invariavelmente uma comunidade de trabalho, o que para ele significa que toda sociedade está sempre em luta com a natureza exterior, ${ }^{6}$ apenas a moderna assim se percebe, pois somente ela se considera em luta. Tal modo de conceber-se a própria relação com a natureza exterior torna essa luta agressiva, em lugar de defensiva, e este "é o resultado de uma longa e complexa evolução, e caracteriza, propriamente, o homem moderno"7

Lima Vaz, por sua vez, chama-nos a atenção para o "lento e inexorável movimento nas camadas profundas da civilização" ${ }^{\prime 8}$ que promove, no mundo moderno e na modernidade, o deslocamento do foco de inteligibilidade da cultura para as formas de vida prática e poiética: "Sociedade e Economia ou Política e Trabalho passaram a ser os polos unificadores da cultura moderna". 9

Mas é claramente com Karl Marx que o trabalho alcançará um estatuto inaudito na história do pensamento ocidental. Na interpretação de Lima

\footnotetext{
${ }^{1}$ Agradeço a leitura prévia e as valiosas sugestões do amigo, interlocutor de tantas horas, Júlio Ferreira de Oliveira - que há quase trinta anos me iniciou nos estudos de Karl Marx -, sem responsabilizá-lo, naturalmente, pelas minhas escolhas, especialmente por eventuais erros e omissões.

${ }^{2}$ Veja-se, por exemplo, REALE, Giovanni. História da filosofia antiga. Trad. de M. Perine e H. C. de Lima Vaz. São Paulo: Loyola, 1995, v. 5, p. 257.

${ }^{3}$ MIGEOTTE, Léopold. Os filósofos gregos e o trabalho na antiguidade. In: MERCURE, D.; SPURK, J. O trabalho na história do pensamento ocidental. Trad. de P.C. R. Reuillard e S. G. Taborda. Petrópolis: Vozes, 2005, p. 18.

${ }^{4}$ MIGEOTTE, L. Os filósofos gregos e o trabalho na antiguidade, p. 18.

${ }^{5}$ RICOEUR, Paul. História e Verdade. Trad. de F. A. Ribeiro. Rio de Janeiro: Forense, 1968, p. 202.

${ }^{6}$ WEIL, E. Filosofia Política. Tradução e apresentação de Marcelo Perine. São Paulo: Loyola, 1990, p. 77.

${ }^{7}$ WEIL, E. Filosofia Política, p. 78.

${ }^{8}$ LIMA VAZ, Henrique Cláudio de. Escritos de Filosofia III. Filosofia e cultura. São Paulo: Loyola, 1997, p. 92.

${ }^{9}$ LIMA VAZ, Henrique Cláudio de. Escritos de Filosofia III, p. 92.
} 
Vaz, o trabalho tem em Marx, assim como a razão na Ilustração e o espírito em Hegel, a função de princípio explicativo do acontecer histórico. Atua, pois, como princípio hermenêutico, permitindo uma visão abrangente da história como história universal. ${ }^{10}$

Lima Vaz pondera ainda que o trabalho desalienado, em sua reconciliação final com a natureza, será o "lugar teórico" no qual se abre, em Marx, a perspectiva da emergência do indivíduo universal como paradigma do indivíduo moderno, "capaz de exercer a práxis instauradora de uma comunidade ética universal". ${ }^{11}$

É oportuno lembrarmos aqui a afirmação do próprio Marx sobre a realidade sensível e representacional do trabalho no mundo moderno: "A posição (Setzung) do indivíduo como um trabalhador, nessa nudez, é propriamente um produto histórico" ${ }^{12}$ Paradoxalmente, esse desnudar-se do ser humano como trabalhador constituirá uma espécie de afirmação às avessas, em que o sujeito se põe de ponta-cabeça e se vê subsumido no devir de um outro - sua própria existência social reificada e autonomizada como uma realidade que se desenvolve por si mesma - o capital. Pudemos expressá-lo deste modo em outro lugar:

Ora, para Marx, é imperativo conceber a riqueza como exteriorização das disposições criativas do ser humano por meio de sua atividade, como desenvolvimento de sua própria natureza. A riqueza é o próprio desenvolvimento da vida humana como tal, e não apenas o seu resultado reificado. A economia burguesa amplia as forças produtivas humanas e, portanto, também esse domínio e essa reprodução da natureza exterior para muito além de qualquer termo de comparação histórico, revelando a própria natureza humana como devir e como contínua negação e ultrapassagem dos limites de um mundo dado. Mas, ao mesmo tempo, toda essa interiorização-exteriorização da natureza como desenvolvimento universal das capacidades do ser humano é assumido por ele próprio como um processo que tem outro sujeito e cujo fim the é completamente estranho (...) Ao final, pois, Marx valoriza o mundo moderno e seu movimento, que é de afirmação e de objetivação do ser humano de fato. Rompe-se o círculo da satisfação

${ }^{10}$ LIMA VAZ, Henrique Cláudio de. Escritos de Filosofia III, p. 125.

${ }^{11}$ LIMA VAZ, Henrique Cláudio de. Escritos de Filosofia III, p. 125.

${ }^{12}$ MARX, Karl; ENGELS, Friedrich. Werke. Berlin: Dietz Verlag, 1956ss (45v), v. 42, p. 384. Ao verter todas as citações diretas das obras de Marx para o português, valemo-nos das ótimas traduções que temos disponíveis, notadamente a de Flávio Kothe, no caso de Das Kapital (MEW 23-25). Cotejamo-la também com a tradução de Rubens Enderle, embora esta se tenha estabelecido a partir da edição da Marx-Engels-Gesamtausgabe, a MEGA, projeto organizado pela Internationale Marx-Engels Institute, com sede em Amsterdã, desde a queda do muro de Berlim. Como por vezes tivemos opções de tradução um pouco diferentes, preferimos referir, de modo uniforme, a paginação do texto em alemão da Marx-Engels-Werke, citada doravante apenas como MEW, como é a forma habitual. Quando foi preciso citar, na última seção deste artigo, uma passagem mais extensa dos Grundrisse (MEW 42), usamos integralmente a cuidadosa tradução de Mario Duayer e Nélio Schneider, editada pela Boitempo, e referimo-la. 
dos antigos por meio da insatisfação constitutiva que move o ser humano rumo à sua autorrealização, à sua autoexpressão, redesenhando sempre os contornos e os caracteres da própria realidade. Mas, ao mesmo tempo em que, nesse processo, o ser humano se põe em movimento e atualiza a sua condição de atividade e devir, fá-lo de um modo que perverte a sua condição de sujeito e de fim de sua própria objetivação universal. Põe-se a serviço e sob as determinações de sua própria exteriorização feita autônoma. Com efeito, essa afirmação é pervertida, ou se constitui às avessas, pois, se por um lado nega o modo não ativo de ser-no-mundo dos antigos, por outro, faz-se hetero-objetivação, ao retirar do ser humano a condição, antes claramente afirmada, de Selbstzweck. ${ }^{13}$

Nos tempos hodiernos, quando se tornou lugar-comum anunciar o desaparecimento do trabalho ${ }^{14}$ - em sentido frequentemente diverso do que vislumbrou Marx -, consideramos mais do que justificável retomar a rica reflexão marxiana sobre um aspecto central dessa afirmação negativa ${ }^{15}$ - como a chamamos - que vem a ser a subsunção formal e real do trabalho no capital.

Dentre os motivos para retomarmos este tema ainda se incluem a sua inarredável e crescente atualidade e o encantamento sempre renovado com a arquitetônica conceptual da reflexão marxiana sobre o processo de trabalho e o processo de valorização - que nos exortam, uma vez mais, ao esforço de compreender a concepção marxiana do capital e algumas de suas implicações fundamentais.

\section{O processo de trabalho: homem, natureza $e$ trabalho}

Considerado em sua estrutura geral, sem se determinar por esta ou aquela forma social, o trabalho é um processo entre o ser humano e a natureza, mas um processo que tem no primeiro termo o seu substrato. Este, "por

\footnotetext{
${ }^{13}$ GUEDES, Édil. A economia como sistema da representação em Karl Marx. São Leopoldo: Editora UNISINOS, 2014, p. 200-201.

14 "Há pelo menos cinquenta anos autores como Marcuse já apontavam que a automatização estava levando os países avançados a inverter a relação entre o tempo dedicado ao trabalho produtivo e o tempo dedicado ao lazer. Certamente, se atentarmos para a quantidade global do tempo necessário para a produção dos mesmos bens e serviços, parece que Marcuse tinha razão, porque esse tempo necessário se reduziu notavelmente, gerando uma grande quantidade de tempo livre. Curiosamente, porém, tal redução não supôs uma redução da semana de trabalho, entre outras razões, porque as empresas preferem reduzir o pessoal, acreditando que aumentar a competitividade exige seguir o imperativo da inovação tecnológica, reduzindo mão-de-obra, já que isso lhes permite poupar subsídios, planos assistenciais e fundos de pensão". CORTINA, Adélia. Cidadãos do mundo: para uma teoria da cidadania. Tradução de S. Cobucci Leite. São Paulo: Loyola, 2005, p. 90-91.

${ }^{15}$ Lima Vaz, refletindo sobre como esta problemática se apresentava ainda nos escritos marxianos de juventude, reflete sobre a inversão da dialética do finis operis (o fim é estatuído pelo agente) e do finis operantis (o fim imanente à obra produzida) na alienação do trabalho: "Nela, o finis operis torna-se um fim em si mesmo e impõe tiranicamente as suas exigências:
} 
sua própria ação, medeia, regula e controla seu metabolismo com a natureza", ${ }^{16}$ conforme a expressão de Marx. Valendo-se de suas forças, e sempre desenvolvendo-as, o ser humano apropria-se da natureza exterior em formas que sejam úteis ou pertinentes à sua vida. ${ }^{17}$ Demudando-a - sustenta Marx - acaba por alterar a sua própria natureza. ${ }^{18}$ Humanizando-a, ao conferir-lhe uma finalidade racional, e ao incorporá-la sensível e significativamente à sua realidade, à sua vida, humaniza-se, forma-se como sujeito humano. ${ }^{19} \mathrm{O}$ trabalho é atividade exclusivamente humana, ${ }^{20}$ em que a imaginação se exterioriza, em que a vontade se orienta ao desígnio que à natureza impôs, ${ }^{21}$ engendrando-o:

Uma aranha executa operações semelhantes às do tecelão, e uma abelha envergonha muitos arquitetos com a estrutura de sua colmeia. Porém, o

a utilidade, o lucro. Então, o trabalho deixa de ser o mediador autêntico, pois já não fundamenta uma verdadeira relação social. O elemento específico da alienação do trabalho é, finalmente, a inversão da relação de poder que, dirigida originariamente do homem ao mundo, se volta agora do mundo ao homem. E como não evocar aqui as cruéis análises de Marx, num dos trechos mais célebres dos Manuscritos de 1844?". Escritos de filosofia. Problemas de fronteira. São Paulo: Loyola, 1986, p. 131-132.

${ }^{16}$ MEW 23, p. 192.

${ }^{17} \mathrm{O}$ ser humano altera as combinações originais dos elementos naturais, modifica-lhes o curso e o sentido, abrindo-lhes um leque ilimitado de novas possibilidades, e assim "submete o jogo de suas forças a seu próprio domínio". MEW 23, p. 192.

${ }_{18}$ MEW 23, p. 193.

${ }_{19}$ MEW 23, p. 193. Como bem o expressou J. F. de Oliveira, esta atividade corresponde a "certa realidade do homem como ser que, para viver, atua sobre o mundo exterior e sobre si mesmo, e muitas vezes sobre si por meio daquele ou vice-versa. Por essa atuação, ele cria aquilo de que necessita, seja a necessidade do estômago, seja a da fantasia, como disse Marx". Ethos e políteia. Os fundamentos da concepção marxiana da economia. São Leopoldo: Editora Unisinos, 2004, p. 145.

${ }^{20}$ MEW 23, p. 193. Veja-se esta bela passagem em que Henrique Cláudio de Lima Vaz reflete sobre o sentido do trabalho como atividade especificamente humana: "Compreender e transformar o mundo para finalizá-lo segundo as exigências e necessidades do sujeito: eis a intenção original que estabelece, entre o homem e o mundo, a relação de trabalho. $\mathrm{O}$ trabalho revela-se, pois, originalmente, como a luta do homem para dar à sua situação no mundo uma significação humana. Trata-se de uma luta: pois o mundo opõe-se ao homem na sua inércia, no seu determinismo, nos seus enigmas, nas suas ameaças, na realidade dos recursos que ao próprio homem são necessários. Mas é a significação humana conferida a esta luta - ou o finalismo humano nela inscrito - que a torna verdadeiramente trabalho. É certo que as "carências sensíveis" do homem, para falar com Marx - se somente delas se tratasse - poderiam ser satisfeitas pelo caminho do instinto. $\mathrm{O}$ homem poderia abrigar-se no seio protetor da natureza para dela receber alimento. Mas, como razão e liberdade - como pessoa -, o homem transcende a natureza e, por isso, a sua relação primordial com ela assume a forma de um afrontamento, de uma conquista, da construção de um sentido humano para a sua presença no mundo: assume a forma do trabalho". Escritos de Filosofia. Problemas de fronteira, p. 127-128. Naturalmente, Lima Vaz não poderá acompanhar Marx a partir daqui, por julgar que a história não se pode circunscrever a esta relação e aos seus desdobramentos, hipostasiando-a, assim, na afirmação do ser e do sentido humanos.

${ }^{21}$ Já no Sistema da vida ética, Hegel concebe o trabalho como objetivação do pensar, em que a apropriação e transformação da natureza imprime nesta última a marca da subjetividade. Leia-se o comentário preciso de José Henrique Santos sobre a inscrição da natureza na ordem da cultura, à medida que esta recebe um sentido humano: "A casa é contradição resolvida: o que era pedra e cal tornou-se parede, o que era árvore, ser vivo, morre para renascer como objeto de cultura, como porta e janela, móvel e utensílio. A casa é a natureza habitada pelo 
que desde o início distingue o pior arquiteto da melhor abelha é o fato de que o primeiro tem a colmeia em sua mente antes de construí-la com a cera. No final do processo de trabalho, chaga-se a um resultado que já estava presente na representação do trabalhador no início do processo, ou seja, um resultado que já existia idealmente. Isto não significa que ele se limite a uma alteração da forma do elemento natural; ele realiza, neste último, ao mesmo tempo, a finalidade (Zweck) pretendida, que, como ele bem o sabe, determina o modo de sua atividade com a força de uma lei, à qual ele tem de subordinar sua vontade. E essa subordinação não é um ato isolado. Além do esforço dos órgãos que trabalham, a atividade laboral exige a vontade orientada a um fim (zweckmäßige Wille), que se manifesta como atenção do trabalhador durante a realização de sua tarefa, e isso tanto mais quanto menos esse trabalho, pelo seu próprio conteúdo e pela modo de sua execução, atrai o trabalhador, portanto, quanto menos este último usufrui dele como jogo de suas próprias forças físicas e espirituais. ${ }^{22}$

Em seu aspecto subjetivo, o processo de trabalho tem como elemento, pois, o próprio trabalho, como atividade orientada e adequada a um fim. Em seu aspecto objetivo, constitui-se dos objetos e dos meios de trabalho. Os objetos de trabalho são a matéria a ser informada - aquela sobre a qual a atividade incide -, e os meios de trabalho são os instrumentos, os utensílios com os quais a atividade pode operar sobre aqueles objetos: "O meio de trabalho é uma coisa ou um complexo de coisas que o trabalhador põe entre si e o objeto do trabalho, e que lhe serve de guia de sua atividade sobre este objeto" ${ }^{23} \mathrm{O}$ objeto de trabalho pode preexistir por natureza, sendo apenas desprendido de sua conexão geral com ela, como o peixe pescado ou o carvalho extraído da floresta virgem. E por esta razão a natureza, como um todo, pode ser dita o objeto universal do trabalho humano. ${ }^{24}$ Mas se o objeto de trabalho foi fruto de trabalho anterior - como cada vez mais o será -, chamamo-lo matéria-prima. A matéria-prima é, pois, objeto constituído como tal pelo trabalho, ou trabalhado para ser objeto de trabalho. ${ }^{25}$

O meio de trabalho pode ser igualmente arrebatado à natureza - que aqui figura como uma espécie de "arsenal original" -, mas se apresentará muito mais frequentemente como um produto, como coisa já trabalhada. ${ }^{26}$ Também o uso e a criação de meios de trabalho caracterizam o processo de trabalho como algo exclusivamente humano: para Marx, não apenas o que se faz, mas principalmente como se faz e com o que se faz - eis o que permite distinguir as diferentes épocas da produção material da vida humana, no

\footnotetext{
homem, manifestação desta liberdade que, respeitando o ser da coisa natural, o transforma e o eleva ao nível do sujeito, como expressão de sua necessidade, mas também de sua vontade livre". Trabalho e riqueza na Fenomenologia do Espírito de Hegel. São Paulo: Loyola, 1993, p. 26-27. ${ }^{22}$ MEW 23, p. 193.

${ }^{23}$ MEW 23, p. 194.

${ }^{24}$ MEW 23, p. 193.

${ }^{25}$ MEW 23, p. 193.

${ }^{26}$ MEW 23, p. 194.
} 
que respeita ao seu grau de desenvolvimento e às circunstâncias sociais da atividade humana. ${ }^{27}$ Além dos meios de trabalho diretamente incluídos em um processo de trabalho específico, existem aqueles que constituem as condições mais gerais de qualquer processo de trabalho. Neste sentido, o próprio ambiente natural figura como meio universal de trabalho, pois dá ao trabalhador o lugar para ficar e o campo de ação..$^{28}$ Mas em um processo desenvolvido, essas condições já serão, também, em grande medida, produtos de trabalhos anteriores. Como vimos, "os produtos são não apenas resultado, mas também condições do processo de trabalho", ${ }^{29}$ pois cada vez mais os meios de produção serão produzidos por trabalhos anteriores. ${ }^{30}$

Tomado o processo em seu conjunto e relativamente ao seu resultado, que é o produto, todos os seus elementos objetivos - objetos e meios de trabalho - podem então considerar-se meios de produção, e a sua dimensão subjetiva - a atividade do trabalhador - pode ser chamada de trabalho produtivo. ${ }^{31}$ Ao final do processo, o trabalho objetiva-se e o objeto, como trabalho incorporado, subjetiva-se:

No processo de trabalho, portanto, a atividade do homem efetua, mediante os meios de trabalho, uma transformação do objeto de trabalho pretendida desde o princípio. O processo extingue-se no produto. Seu produto é um valor de uso, uma matéria natural adaptada às necessidades humanas por meio da modificação de sua forma. O trabalho se uniu ao seu objeto. Ele está objetivado e o objeto está trabalhado. O que do lado do trabalhador aparecia na forma de inquietação (Unruhe) agora se manifesta, do lado do produto, como propriedade imóvel (ruhende Eigenschaft), na forma do ser. Ele fiou, $e$ o produto é um fio. ${ }^{32}$

Os meios de produção são todos, portanto, valores de uso. Mas o são apenas potencialmente. É somente o trabalho que os atualiza, que os põe em relação conforme a estratégia traçada e os fins pretendidos:

Uma máquina que não serve no processo de trabalho é inútil. Além disso, sucumbe à força destruidora do metabolismo natural. O ferro enferruja, a madeira apodrece. Fio que não é usado para tecer ou fazer malha é algodão estragado. O trabalho vivo deve apoderar-se dessas coisas, despertá-las dentre os mortos, transformá-las de valores de uso apenas possíveis em valores de uso reais e efetivos. Lambidas pelo fogo do trabalho, apropriadas por ele como seus corpos, animadas a exercer as funções conceptuais e vocacionais, é verdade que serão também consumidas, porém de um modo orientado a um fim (zweckvoll), como elementos constitutivos de novos valores de uso, de no-

\footnotetext{
${ }^{27}$ MEW 23, 194-195. Eric Weil, a este respeito, pondera: “O animal é capaz de fazer esforços e transformar o dado, mas só o homem social trabalha em sentido estrito: no trabalho e pelo trabalho o homem pode transformar a sua maneira de trabalhar". Filosofia politica, p. 81. Grifos meus.

${ }^{28}$ MEW 23, p. 195.

${ }^{29}$ MEW 23, p. 196. Grifos meus.

${ }^{30}$ MEW 23, p. 196.

${ }^{31}$ MEW 23, p. 195.

${ }^{32}$ MEW 23, p. 195.
} 
vos produtos, aptos a incorporar-se ao consumo individual como meios de subsistência ou a um novo processo de trabalho como meios de produção. ${ }^{33}$

Temos até aqui, como se fez saber desde o início, as relações basilares entre os aspectos subjetivo e objetivos de um processo de trabalho assumido e apresentado em sua estrutura universal. Foram, portanto, abstraídas quaisquer determinidades sociais dos elementos e relações que o constituem. O trabalho e seu processo, assim considerados, são, no dizer de Marx, a condição universal do metabolismo (Stoffwechsell) entre homem e natureza, condição natural eterna (ewige) da vida humana. ${ }^{34}$ No entanto, a identificação dessas condições inalienáveis não autoriza deduzir a existência de um processo de trabalho informe, que não se determinasse por uma ordem de relações entre os agentes sociais humanos e seus sentidos:

O processo de trabalho, como o apresentamos em seus momentos simples e abstratos, é atividade orientada a um fim para a fabricação de valores de uso, apropriação do natural para as necessidades humanas, condição universal do metabolismo entre homem e natureza, condição natural eterna da vida humana e, por isso, independente de qualquer forma dessa vida, ou melhor, comum a todas as suas formas sociais. Por isso, não tivemos necessidade de apresentar o trabalhador em sua relação com outros trabalhadores. $\mathrm{O}$ homem e seu trabalho, de um lado, a Natureza e suas matérias, do outro, bastavam. Assim como o sabor do trigo não revela quem o plantou, tampouco esse processo [assim apresentado] nos revela as condições em que ele se ocorre, se sob o açoite brutal do feitor de escravos ou sob o olhar ansioso do capitalista, se Cincinnatus o realiza ao cultivar suas poucas jugera, ou o selvagem, ao abater uma fera com uma pedra. ${ }^{35}$

Seguimos rigorosamente, até aqui, a exposição marxiana do processo de trabalho em sua generalidade. As perguntas que ora nos competem, porquanto motivadoras deste artigo, serão as seguintes: como o processo de trabalho se converte em processo de valorização - o processo mesmo do capital - e o que isto implica? Nos limites deste artigo, não nos caberá recuperar a gênese lógico-histórica do capital em Marx como relação social definidora da economia e da vida social modernas, marcadas radicalmente pelo fetichismo. Importa-nos mostrar que, para Marx, o capital não constitui apenas mais um modo de o processo de trabalho informar-se socialmente, mas uma forma social bastante complexa das relações de produção, que

\footnotetext{
${ }^{33}$ MEW 23, p. 198. "Em suma, as coisas atuam conforme as determinações que o trabalho confere a elas, não obstante essas determinações só possam atuar sobre as propriedades sensíveis delas. Mas se as coisas não realizam as suas funções, acabam sendo consumidas pela própria natureza, e devêm inúteis para a vida humana". GUEDES, Édil. A economia como sistema da representação, p. 207.

${ }^{34}$ MEW 23, 198.

${ }^{35}$ MEW 23, p. 198-199. Como se verá na subsunção real do trabalho ao capital: "Mesmo o processo considerado precipuamente em sua dimensão técnico-material há de modificar sensivelmente o seu modo de ser em função daquelas determinidades". GUEDES, Édil. $A$ economia como sistema da representação em Karl Marx, p. 207.
} 
se autonomiza e conduz a uma inversão radical das dimensões originais do processo de produção. O capital dá existência ao trabalho e ao seu processo como momentos seus, como parte fundamental, mas radicalmente subordinada, de sua própria dinâmica autoexpansiva. A isto se chamará, nos termos propostos por Marx, a subsunção formal e real do trabalho no capital.

\section{O processo de valorização: subsunção formal e real do trabalho no capital}

Assim como o trabalho, o capital também se define como um processo, como um devir - a autovalorização do valor. O capital é essa complexa relação social na qual o valor - representado no dinheiro, do qual o capitalista é o portador - torna-se sujeito de um processo em que ele, a partir de si, encadeando uma série de momentos mediadores, gera valor e mais-valor. É um valor que pare valor, para usarmos esta imagem tão expressiva e recorrente para Marx. Só assim o dinheiro circula e atua como capital. ${ }^{36}$ O capital torna-se capital apenas quando:

por meio de uma mudança constante das formas de dinheiro e mercadoria, modifica a sua própria grandeza, enquanto mais-valor se repele de si mesmo, enquanto valor original, se autovaloriza. Pois o movimento, pelo qual ele adiciona mais-valor, é seu próprio movimento, sua valorização (Verwertung), logo autovalorização (Selbstverwertung). Ele recebeu a qualidade oculta de gerar valor porque ele é valor. Ele pare filhotes vivos ou ao menos põe ovos de ouro. ${ }^{37}$

Mas como esta dinâmica se desenvolve? O capitalista escolhe e adquire, no mercado, todos os fatores - subjetivos e objetivos - necessários à realização de um processo de trabalho. Em seguida, põe-nos em relação:

Nosso capitalista põe-se então a consumir a mercadoria que ele comprou, a força de trabalho, isto é, ele faz o portador da força de trabalho, o traba-

\footnotetext{
${ }^{36}$ Assim como o capital se apresenta sob as suas formas elementares (Elementarformen), que são a mercadoria e o dinheiro, o capitalista também imediatamente se apresenta como o seu possuidor. Mas isso não o torna capitalista, assim como o ser mercadoria ou dinheiro não os faz capital em si e para si. Estes só serão capital, assim como o seu possuidor só será capitalista, "mediante determinadas premissas". Antes disso, só o são potencialmente. Cf. MARX, Karl. Resultate des unmittelbaren Produktionsprozesses. Das Kapital. I. Buch. Der Produktionsprozess des Kapitals. VI. Kapitel. Frankfurt: Verlag Neue Kritik, 1969, p. 3 (459). Este notável escrito de Marx, produzido entre 1863 e 1866, mas que se deu a conhecer apenas em 1933 e se tornou mais conhecido como o Capítulo VI Inédito de O Capital, constitui uma das referências essenciais do nosso texto. Para as citações em português, consultamos muitas vezes a edição brasileira da Editora Moraes, de 1985, que na verdade toma como base a tradução portuguesa de Antônio Ribeiro e a coteja com outras versões em línguas neolatinas. Pelas mesmas razões já apresentadas anteriormente (ver a nota 11), preferimos indicar sempre a paginação da edição alemã, seguida da numeração encontrada no caderno de Marx.

${ }^{37}$ MEW 23, p. 169.
} 
lhador, consumir os meios de produção mediante seu trabalho. A natureza geral do processo do trabalho não se altera, naturalmente, por executá-lo o trabalhador para o capitalista, em vez de para si mesmo. Mas também o modo específico de fazer botas ou de fiar não pode alterar-se de início pela intromissão do capitalista. Ele tem de tomar a força de trabalho, de início, como a encontra no mercado e, portanto, também seu trabalho da maneira como se originou em um período em que ainda não havia capitalistas. ${ }^{38}$

O que almeja o capitalista? Responde-nos Marx:

O produto - a propriedade do capitalista - é um valor de uso, fio, botas etc. Mas embora as botas, por exemplo, constituam de certo modo a base do progresso social e nosso capitalista seja um decidido progressista, ele não fabrica as botas por causa delas mesmas. Na produção de mercadorias, o valor de uso não é, de modo algum, a coisa qu'on aime pour lui-même. Produzem-se aqui valores de uso somente porque e na medida em que sejam substrato material, portadores do valor de troca. E para nosso capitalista, trata-se de duas coisas. Primeiro, ele quer produzir um valor de uso que tenha um valor de troca, um artigo destinado à venda, uma mercadoria: Segundo, ele quer produzir uma mercadoria cujo valor seja mais alto que a soma dos valores das mercadorias exigidas para produzi-la, os meios de produção e a força de trabalho, para as quais adiantou seu bom dinheiro no mercado. Quer produzir não só um valor de uso, mas uma mercadoria, não só valor de uso, mas valor, e não só valor, mas também mais-valor. ${ }^{39}$

Ora, o capital reúne os elementos do processo de trabalho, fá-los produzir valores de uso, mas valores de uso que sejam necessariamente permutáveis, negociáveis no mercado. Em uma palavra, mercadorias - coisas de valor. Sob o capital, o processo de trabalho se converte em processo de produção mercantil, portanto, de produção de valor. No entanto, a produção mercantil não será capitalista se não tiver como motivo indutor e como finalidade última, não a simples recuperação do valor inicialmente empregado, mas a geração de valor excedente, de mais-valor. Assim, a atividade do trabalhador no interior da produção capitalista converte-se em atividade do capital. ${ }^{40}$

Os meios de produção são adquiridos pelo capitalista como mercadorias, portanto são sua propriedade. São um novo modo de existência do capital, ou melhor, um momento de sua existência como valor autovalorizante. $\mathrm{O}$ capital-dinheiro converte-se em capital-mercadoria - os meios de produção, agora vertidos em capital constante. A outra parte do gasto do capitalista realizou-se para adquirir a mercadoria força de trabalho - doravante capital

\footnotetext{
${ }^{38}$ MEW 23, p. 199. Em Resultate des unmittelbaren Produktionsprozesses, Marx faz a seguinte observação: "A transformação do próprio modo de produção por meio da subordinação do trabalho ao capital só pode ocorrer posteriormente...". Ibidem, p. 3 (459) Projeta-se aqui o que Marx chamou de subordinação real do trabalho ao capital. Falaremos dela mais adiante. ${ }^{39}$ MEW 23, p. 200-201.

${ }^{40}$ GUEDES, Édil, A economia como sistema da representação em Karl Marx, p. 207.
} 
variável. Postas em uso, estas mercadorias compradas pelo capitalista se fazem ingredientes de um processo de trabalho, de qualquer processo de trabalho. No entanto, assumem aqui, tanto o trabalho vivo como o conjunto dos meios de produção - os meios e objetos de trabalho - a condição de capital-produtivo, outro momento da existência do capital. Diz Marx: "Considerado como função pessoal, na realidade, o trabalho é função do trabalhador, não do capitalista". ${ }^{41}$ Mas, considerado no processo de produção capitalista, desde o seu próprio ponto de vista, "o trabalhador é o que o capitalista recebe dele no processo de trabalho", ${ }^{42}$ ou seja, ele é o valor de uso pelo qual se pagou. Ele é parte daquilo em que o capital, nesta fase decisiva do processo de autovalorização, converteu-se. A parte mais importante.

A parte do capital-dinheiro que se converte em força de trabalho constitui o capital variável, porque corresponde ao adiantamento do valor da reprodução da própria força de trabalho, que deve ser obtido com o próprio uso da força de trabalho pelo capital. Mas a força de trabalho deve ser capaz de gerar um valor sempre maior do que este. A diferença entre o valor que lhe devolve o custo da própria subsistência e o valor total que ela gera no processo de trabalho é o mais-valor, a razão de ser do capital, o seu télos. Por isso, como o reflete Marx, a força de trabalho é grandeza fluida, em devir, variável, e não grandeza havida, como aquela que corresponde ao valor dos elementos do capital constante, os meios de produção, que devem apenas ser repostos. ${ }^{43}$

Para Marx, a força de trabalho, adquirida pelo capitalista e convertida em parte do capital, constitui a levedura que o faz entrar em fermentação: ${ }^{44} \mathrm{O}$ trabalhador objetiva-se agora de modo heterônomo, não em um objeto seu, mas no material da valorização do capital..$^{45}$ Sob a ordem do capital, incluído em seu movimento, submetido à sua lógica, o processo de trabalho, como um todo, assume-se como objeto de consumo do capital, que não visa senão à reprodução alargada de si mesmo. Na contundente expressão de Marx, o processo de trabalho representa-se, objetivamente, como um processo entre coisas que o capitalista comprou, entre coisas que lhe pertencem:

o produto é propriedade do capitalista, e não do produtor direto, do trabalhador. O capitalista paga, por exemplo, o valor de um dia da força de trabalho. A sua utilização, como a de qualquer outra mercadoria, por

\footnotetext{
${ }^{41}$ MARX, Karl. Resultate des unmittelbaren Produktionsprozesses, p. 11 (463).

${ }^{42}$ MARX, Karl. Resultate des unmittelbaren Produktionsprozesses, p. 11 (463).

${ }^{43}$ Cf. MARX, Karl. Resultate des unmittelbaren Produktionsprozesses, p. 11-12 (463) É certo que, se uma parte do capital se faz grandeza variável, isto se torna verdadeiro para o capital como um todo.

${ }^{44}$ Veja-se, por exemplo, MEW 42, p. 220. Conferir também GUEDES, Édil, A economia como sistema da representação, p. 207.

${ }^{45}$ MEW 42, p. 220.
} 
exemplo, a de um cavalo que alugou por um dia, pertence-lhe, portanto, durante o dia. Ao comprador da mercadoria pertence a utilização da mercadoria, e o possuidor da força de trabalho dá, de fato, apenas o valor de uso que vendeu ao dar seu trabalho. A partir do momento em que ele entrou na oficina do capitalista, o valor de uso de sua força de trabalho, portanto, sua utilização, o trabalho, pertence ao capitalista. O capitalista, mediante a compra da força de trabalho, incorporou o próprio trabalho, como fermento vivo, aos elementos mortos constitutivos do produto, que lhe pertencem igualmente. Do seu ponto de vista, o processo de trabalho é apenas o consumo da mercadoria, força de trabalho por ele comprada, que só pode, no entanto, consumir ao acrescentar-lhe meios de produção. O processo de trabalho é um processo entre coisas que o capitalista comprou, entre coisas que the pertencem. O produto desse processo pertence-lhe de modo inteiramente igual ao produto do processo de fermentação em sua adega. ${ }^{46}$

O processo de trabalho é assim subsumido ${ }^{47}$ no processo de autovalorização do valor:

Como unidade do processo de trabalho e processo de formação de valor, o processo de produção é processo de produção de mercadorias; como unidade do processo de trabalho e processo de valorização, é ele processo de produção capitalista, forma capitalista da produção de mercadorias. ${ }^{48}$

No processo de trabalho agora absorvido pelo processo de autoprodução do capital, os meios de produção (objetos e meios de trabalho) deixam de ser a sua dimensão passiva, e o processo deixa de ser do trabalho, pois este não é mais a unidade que o governa (die ihn beherrschende Einheit). ${ }^{49}$

Perde-se assim a identidade entre processo de produção e processo de trabalho. Mas tal condição, nos termos em que a expusemos, define tão-somente a subsunção formal do trabalho no capital para Marx. A subsunção formal não implica imediatamente o estabelecimento de um substrato técnico-material especificamente capitalista. $\mathrm{O}$ capital subordina a si e inclui em si o processo de trabalho que encontrou, adquirindo os seus elementos do modo como originalmente os encontrou. A subsunção real corresponde à alteração progressiva da identidade da própria dimensão técnico-material

\footnotetext{
${ }^{46}$ MEW 23, p. 200. Grifos meus.

47 Subsumir tem origem no latim subsumĕre, que significava originalmente "tomar sob", "apropriar-se de". Passou depois a utilizar-se também com o sentido de "incluir", "subordinar", "sujeitar", "compreender em si". Subsumtion foi o termo técnico utilizado por Marx em Resultate des unmittelbaren produktions Prozess, para referir a conversão do processo de trabalho em momento da autoprodução do capital. Em Das Kapital, curiosamente, Marx usou apenas o substantivo Unterordnung, que se pode verter em "subordinação" ou "pôr sob a ordem". Parece-nos mais apropriado o substantivo Subsumtion, que vai além da ideia de subordinação. Embora a contemple, reforça-a e aprofunda-a, acrescentando-se também, de modo mais direto, o sentido de inclusão. Subsumido no capital, o trabalho é posto sob a ordem do capital e nela absorvido.
}

${ }^{48}$ MEW 23, p. 211.

${ }^{49}$ MEW 42, p. 593. 
da produção pelo capital, submetendo-a às suas necessidades de autovalorização. Tanto os meios de produção quanto a força de trabalho são elementos em que, no ato de sua aquisição, o capital se converteu, mas que se contrapõem no processo de produção, como trabalho vivo e trabalho morto, este último o modo de existência próprio do capital, os meios de produção autonomizados, como consumação real da subsunção do trabalho, e cujo papel é "sugar trabalho vivo". ${ }^{50}$ A maquinaria se torna "verdadeiro amo do trabalho vivo". ${ }^{51}$

Os meios de produção atuam doravante como a materialização do capital em estrutura produtiva autônoma. É a força de trabalho que é consumida por essa estrutura como capital variável, como mercadoria cuja utilidade é exatamente ser fonte de valor.$^{52}$ No exercício da atividade produtiva, o princípio subjetivo dá lugar progressivamente a um princípio objetivo, o que se consolida com a passagem da manufatura à maquinofatura. Diferentemente do trabalho artesanal, no qual os meios de produção devem adequar-se ao trabalhador, aqui é a força de trabalho que tem de acomodar-se ao tempo, ao ritmo e ao modus operandi da máquina, e, por que não dizê-lo, ao próprio modus essendi dela. ${ }^{53}$ Marx sintetiza-o: "A atividade do trabalhador, limitada a uma mera abstração da atividade, é determinada e regulada em todos os seus aspectos pelo movimento da maquinaria, e não o inverso" ${ }^{54}$ Mostrando-se como a própria fisionomia do capital no processo de produção, "a maquinaria é a máxima autonomização possível do meio de trabalho em relação ao trabalhador". ${ }^{55} \mathrm{E}$ é de tal modo significativa a inversão operada pela subsunção formal e real do trabalho no capital que, no limite, se pode dizer: é a máquina que usa produtivamente o trabalhador. ${ }^{56}$

O grande objetivo é a geração de mais-valor relativo, o que apenas se obtém com o aumento da produtividade. As importantes mudanças na direção da subsunção real do trabalho processam-se visando sempre ao prolongamento, relativo à mesma jornada, do tempo que o trabalhador trabalha para o capital em relação ao tempo em que ele trabalha, ainda que indiretamente, para si próprio.

\footnotetext{
${ }^{50}$ MARX, Karl. Resultate des unmittelbaren Produktionsprozesses, p. 11 (463). "Os meios de produção aparecem já unicamente como sorvedouros do maior quantum possível de trabalho vivo". Ibidem, p 16 (465).

${ }^{51}$ Resultate des unmittelbaren Produktionsprozesses, p. 11 (403)

${ }^{52}$ Cf. GUEDES, Édil. A economia como sistema da representação em Karl Marx, p. 208. Portanto, "a massa dos meios de produção disponível deve ser suficiente não só para absorver o trabalho necessário, mas também o trabalho excedente". MARX, K. Resultate des unmittelbaren Produktionsprozesses, p. 15-16 (465).

${ }^{53}$ Cf. GUEDES, Édil. A economia como sistema da representação em Karl Marx, p. 161-162. Ver também a reflexão desenvolvida no item 3.2.2., "O processo de trabalho como representação". ${ }^{54}$ MEW 42, p. 593.

${ }_{55}^{5}$ GUEDES, Édil. A economia como sistema da representação em Karl Marx, p. 215.

56 "Não é o trabalhador que emprega os meios de produção, são os meios de produção que empregam o trabalhador". MARX, K. Resultate des unmittelbaren Produktionsprozesses, p. 16 (465).
} 
A força de trabalho se torna a própria força do capital, o que além de desrealizar o trabalhador como sujeito, ainda atua para empobrecê-lo:

Esta força que conserva o valor e cria novo valor é, por conseguinte, a própria força (Kraft) do capital, ${ }^{57}$ e este processo aparece como processo de autovalorização (Selbstverwertung) do capital, melhor dizendo, de empobrecimento (Verarmung) do trabalhador, que ao criar de si o valor, cria-o ao mesmo tempo como um valor que the é alheio. ${ }^{58}$

É preciso insistir, dirá Marx, contra o fetichismo dos economistas políticos, ${ }^{59}$ que essas não são determinações universais do processo de trabalho, assim como as propriedades capitalistas dos elementos do processo não são o que lhes diz respeito como coisas. Elas são suas determinações econômicas, que exprimem relações de produção determinadas, mas que aparecem como propriedades naturais dessas mesmas coisas. Apenas no interior dessas relações, sob a forma capital, as condições de trabalho tornam-se autônomas, submetendo o trabalhador aos fins reificados que encarnam. ${ }^{60} \mathrm{Na}$ esfera da circulação, capitalista e trabalhador são igualmente mercadores - vendedores e compradores de mercadorias. O capitalista compra a força de trabalho do trabalhador. $\mathrm{O}$ trabalhador compra dos capitalistas os seus meios de vida. Mas a força de trabalho, uma vez negociada, entra no processo de valorização como seu ingrediente chave. E ela não tem como entrar, senão pelo ingresso da pessoa do trabalhador, na condição de mera força de trabalho, mero valor de uso do capital, neste processo. ${ }^{61} \mathrm{O}$ capitalista só o é efetivamente quando, depois de adquirir a força de trabalho, subordina-a a si, convertendo a pessoa do trabalhador em trabalho personificado, e atuando, ele próprio, doravante, como capital personificado: "As funções que

\footnotetext{
${ }^{57}$ Grifo meu.

${ }^{58}$ MARX, K. Resultate des unmittelbaren Produktionsprozesses, p. 16 (465).

${ }^{59}$ Resultate des unmittelbaren Produktionsprozesses, p. 11 (463).

${ }^{60}$ Resultate des unmittelbaren Produktionsprozesses, p. 17 (466).

${ }^{61}$ Resultate des unmittelbaren Produktionsprozesses, p 17 (466). Embora se abstraia formalmente como mercadoria, a força de trabalho não pode abstrair-se realmente de quem a vende. $\mathrm{O}$ trabalhador sai da esfera da circulação, do mundo do contrato, como um indivíduo presumidamente autônomo e entra na esfera da produção como coisa heterônoma. Ele não entra no processo de produção como pessoa, mas como mera força de trabalho objetificada, que se fez propriedade do capital: "Ao sair dessa esfera da circulação simples ou da troca de mercadorias, da qual o livre-cambista vulgaris extrai intuições, conceitos e critérios para seu juízo sobre a sociedade do capital e do trabalho assalariado, já se transforma, assim parece, em algo a fisionomia de nossa dramatis personae. $\mathrm{O}$ antigo possuidor de dinheiro marcha adiante como capitalista, segue-o o possuidor de força de trabalho como seu trabalhador; um, cheio de importância, sorriso satisfeito e ávido por negócios; o outro, tímido, contrafeito, como alguém que levou a sua própria pele para o mercado e agora não tem mais nada a esperar, exceto o - curtume". MEW 23, p. 190-191. Parece-nos oportuno reproduzir o comentário que fizemos a esta passagem: "Exposta a relação em sua natureza imediatamente mercantil, Marx nos convida a abandonar a esfera ruidosa, existente na superfície e acessível a todos os olhos', para seguir o capitalista e o trabalhador 'ao local oculto da produção'. Lá dentro, no contexto das relações de produção propriamente capitalistas, o simbolismo vinculado ao trópos dos dois indivíduos, como expressão de sua personalidade no ethos econômico, transforma-se substancialmente". GUEDES, Édil. A economia como sistema da representação, p. 239.
} 
o capitalista exerce não são mais do que as funções do próprio capital - do valor que se valoriza sugando trabalho vivo - exercidas com consciência e vontade" ${ }^{62} \mathrm{O}$ trabalho - a atualização da força de trabalho - pertence ao capitalista como "substância criadora e incrementadora de riqueza" ${ }^{63}$

\section{Contradições e fraquezas do capital - limites da subsunção do trabalho}

No processo de produção da vida social humana, a subsunção formal e real do trabalho no capital realiza essa conversão do sujeito em objeto e vice-versa, que corresponde à própria alienação do trabalho. ${ }^{64}$ Ela é um complexo de relações de dominação invertidas: da coisa sobre o homem, do trabalho morto sobre o vivo, do produto sobre o produtor, dos meios de trabalho sobre a força de trabalho, do capital sobre o trabalhador. Mas Marx considera imprescindível atravessar essa forma antitética de nossa existência ${ }^{65}$. E visto o processo em perspectiva - projeta Marx - este encaminha a sua própria suprassunção:

Considerada historicamente, esta conversão aparece como o momento de transição que é necessário para impor, às expensas da maioria, a criação da riqueza enquanto tal, quer dizer, o desenvolvimento inexorável das forças produtivas do trabalho social, única base material de uma sociedade humana livre. ${ }^{66}$

Esse papel e essa legitimação históricos do capital foram afirmados por Marx em outras tantas passagens, de escritos diversos, como em Das Kapital:

O desenvolvimento das forças produtivas do trabalho social é a tarefa (Aufgabe) e justificativa (Berechtigung) histórica do capital. Precisamente com isso ele cria, sem que esteja consciente, as condições materiais de uma forma de produção superior. ${ }^{67}$

Não nos caberia agora inventariá-las, nem mesmo tomá-las diretamente como objeto de reflexão. Nossa motivação é tão-somente identificar e destacar, nos textos de Marx sobre a subsunção progressiva do trabalho no

\footnotetext{
${ }^{62}$ MARX, K. Resultate des unmittelbaren Produktionsprozesses, p. 17 (466). “O capital expropria os trabalhadores de seu domínio do processo de trabalho, e os próprios capitalistas tornam-se agentes funcionais do capital". SPURK, J. A noção de trabalho em Karl Marx. In: MERCURE, D.; SPURK, J. O trabalho na história do pensamento ocidental. Trad. de P.C. R. Reuillard e S. G. Taborda. Petrópolis: Vozes, 2005, p. 198.

${ }^{63}$ Resultate des unmittelbaren Produktionsprozesses, p 17 (466).

${ }^{64}$ Resultate des unmittelbaren Produktionsprozesses, p 18 (466).

${ }^{65}$ Resultate des unmittelbaren Produktionsprozesses, p 18 (466).

${ }^{66}$ Resultate des unmittelbaren Produktionsprozesses, p 18 (466).

${ }^{67}$ MEW 25, p. 269.
} 
capital, algumas fraquezas e contradições que, na visão deste pensador, abrem caminho para a superação real do capital, e assim permitem ou ensejam tal projeção histórica, na qual se manifesta a esperança marxiana de um tempo qualitativamente novo para a vida social humana, o verdadeiro reino da liberdade. ${ }^{6}$

A primeira observação é que, nesta relação de subordinação e inclusão, aparentemente resta certa superioridade do trabalhador sobre o capitalista, irredutível à reificação plena, mesmo no contexto da maquinofatura, em que se determina a radicalização do processo de subsunção do trabalho. De que se trata? Marx pondera que o capitalista só existe no interior da relação-capital: "criou raízes nesse processo de alienação e nele encontra a sua satisfação absoluta". ${ }^{69}$ Mas - ao ver de Marx - o trabalhador, não! Ele percebe, em última instância, que a sua condição não se limita essencialmente a essa forma. Como vítima, "acha-se de imediato em situação de rebeldia e o sente como um processo de sujeição".$^{70} \mathrm{O}$ processo de trabalho antecede historicamente e precede ontologicamente o processo de valorização, de modo que a ele, evidentemente, não se limita, e o trabalhador tem alguma consciência disto. Também do lado do capitalista, outra limitação se vê exposta. Vimos como o processo de trabalho se tornou apenas um meio do processo de valorização, como finalidade objetiva do capital. Mas essas finalidades precisam encarnar-se, subjetivamente, como "o afã e a finalidade racionalizados do entesourador", e esta condição não deixa de manifestar notável debilidade:

Conteúdo absolutamente mesquinho e abstrato, que, sob certo ponto de vista, faz o capitalista aparecer como que submetido a uma servidão para com a relação do capital que é igual, embora também de outra maneira, à do seu polo oposto, à do trabalhador. ${ }^{71}$

Vê-se o caráter impessoal e reificante da relação, mesmo para o capitalista, porque o capitalista é inexoravelmente preso à lógica do capital, já que o capital depende do trabalhador para ter vida, para existir como valor que gera valor. Já o trabalhador e seu processo são realidades que não se circunscrevem ao tempo do capital, à sua história própria ou contemporânea.

Outra fraqueza do capital revela-se como uma contradição bastante objetiva: a valorização depende do mais-valor relativo, que consiste em reduzir sistematicamente a parte da jornada de trabalho que gera o valor destinado a remunerar o próprio trabalhador. Aumenta-se, então, por consequência, a parte excedente desta jornada, o mais-trabalho, que se converterá ulteriormente em mais-valor - em remuneração do capital. Ora, no limite, o

\footnotetext{
${ }^{68}$ MEW 25, p. 828.

${ }^{69}$ Resultate des unmittelbaren Produktionsprozesses, p. 18 (466).

${ }^{70}$ Resultate des unmittelbaren Produktionsprozesses, p. 18 (466).

${ }^{71}$ Resultate des unmittelbaren Produktionsprozesses, p. 18 (467).
} 
capital expulsa do seu processo, progressivamente, o trabalho vivo, o seu fermento, aquilo que o anima, que faz dele um processo de valorização. O processo de trabalho é reduzido a uma parte ínfima do processo de produção. Retira de sua própria ordem aquilo que sob ela havia sido posto, permitindo que o trabalhador se veja novamente diante da máquina, diante das condições objetivas do processo de trabalho, e não subsumido nelas. Como escreveu Marx nos Grundrisse, o desenvolvimento do capital derroga o próprio capital, destituindo a sua legalidade própria. Afinal, di-lo Marx, a lei do valor acabará por perder a sua a validade, com o trabalho massificado - como esforço cronologicamente mensurável - deixando de ser o seu substrato, e deixando também de ser a fonte de toda riqueza material:

Não é mais o trabalhador que interpõe um objeto natural modificado como elo mediador entre o objeto e si mesmo; ao contrário, ele interpõe o processo natural, que ele converte em um processo industrial, como meio entre ele e a natureza inorgânica, da qual se assenhora. Ele se coloca ao lado do processo de produção, em lugar de ser o seu agente principal. Nessa transformação, o que aparece como a grande coluna de sustentação da produção e da riqueza não é nem o trabalho imediato que o próprio ser humano executa nem o tempo que ele trabalha, mas a apropriação de sua própria força produtiva geral, sua compreensão e seu domínio da natureza por sua existência como corpo social - em suma, o desenvolvimento do indivíduo social. (...) Tão logo o trabalho na sua forma imediata deixa de ser a grande fonte da riqueza, o tempo de trabalho deixa, e tem de deixar, de ser a sua medida e, em consequência, o valor de troca deixa de ser [a medida] do valor de uso. O trabalho excedente da massa deixa de ser condição para o desenvolvimento da riqueza geral, assim como o não trabalho dos poucos deixa de ser condição do desenvolvimento das forças gerais do cérebro humano. Com isso, desmorona a produção baseada no valor de troca, e o próprio processo de produção material imediato é despido da forma da precariedade e contradição. [Dá-se] o livre desenvolvimento das individualidades e, em consequência, a redução do tempo de trabalho necessário não para pôr trabalho excedente, mas para a redução do trabalho necessário da sociedade como um todo a um mínimo, que corresponde então à formação artística, científica etc. dos indivíduos por meio do tempo liberado e dos meios criados para todos eles. O próprio capital é a contradição em processo, [pelo fato] de que procura reduzir o tempo de trabalho a um mínimo, ao mesmo tempo que, por outro lado, põe o tempo de trabalho como única medida e fonte da riqueza. Por essa razão, ele diminui o tempo de trabalho na forma do trabalho necessário para aumentá-lo na forma do supérfluo; por isso, põe em medida crescente o trabalho supérfluo como condição - questão de vida e morte - do necessário. Por um lado, portanto, ele traz à vida todas as forças da ciência e da natureza, bem como da combinação social e do intercâmbio social, para tornar a criação da riqueza (relativamente) independente do tempo de trabalho nela empregado. Por outro lado, ele quer medir essas gigantescas forças sociais assim criadas pelo tempo de trabalho e encerrá-las nos limites requeridos para conservar o valor já criado como valor. (...) A natureza não constrói máquinas nem 
locomotivas, ferrovias, telégrafos elétricos, máquinas de fiar automáticas etc. Elas são produtos da indústria humana; material natural transformado em órgãos da vontade humana sobre a natureza ou de sua atividade na natureza. Elas são órgãos do cérebro humano criados pela mão humana; força do saber objetivada. ${ }^{72}$

Surpreendentemente, a radicalização da subsunção do trabalho se revelará, no texto marxiano, não apenas insustentável - por força de suas contradições endógenas - mas também - e principalmente - promotora das condições materiais do trabalho realmente livre. $\mathrm{O}$ desaparecimento do trabalho necessário, como o segmento da jornada que corresponde à remuneração do trabalhador - o valor da sua força de trabalho - conquista nova e alvissareira significação, representando o desaparecimento do trabalho dominado pelo imperativo da necessidade. Para Marx, sabemo-lo, o ser humano só produz verdadeiramente quando libertado das suas necessidades. ${ }^{73} \mathrm{O}$ sentido de uma sociedade livre permitida pelo desdobramento final desse processo deve-se, portanto, a uma significativa mudança no caráter do trabalho, que perde a sua condição original, de depender das limitações da natureza, do corpo, da atividade sensível, libertando-se para realizar-se mais plenamente como atividade autoexpressiva.

\section{Referências Bibliográficas}

BENSAÏD, Daniel. Marx, o intempestivo. Grandezas e misérias de uma aventura crítica. Trad. de L. C. M. Guerra. Rio de janeiro: Civilização Brasileira, 1999.

BORGES NETO, João Machado. Valor e esgotamento do capitalismo nos Grundrisse. In: PAULA, João Antônio de. (org.) O ensaio geral: Marx e a crítica da economia política (1857-1858). Belo Horizonte: Autêntica, 2010, p. 161-174.

CORTINA, Adélia. Cidadãos do mundo: para uma teoria da cidadania. Tradução de S. Cobucci Leite. São Paulo: Loyola, 2005.

LIMA VAZ, Henrique Cláudio de. Escritos de Filosofia III. Filosofia e cultura. São Paulo: Loyola, 1997.

LIMA VAZ, Henrique Cláudio de. Escritos de filosofia. Problemas de fronteira. São Paulo: Loyola, 1986.

MARX, Karl. Capítulo VI inédito de O Capital: resultados do processo de produção imediata. São Paulo: Moraes, 1985.

\footnotetext{
${ }^{72}$ MEW 42, p. 601-602. MARX, Karl. Grundrisse. Trad. de M. Duayer e N. Schneider. São Paulo: Boitempo; Rio de Janeiro, Editora UFRJ, 2011, p. 589-591.

${ }^{73}$ MEW, Ergänzungsband. Schriften bis 1844. Erster Teil, p. 517.
} 
MARX, Karl. Grundrisse. Trad. de M. Duayer e N. Schneider. São Paulo: Boitempo; Rio de Janeiro, Editora UFRJ, 2011.

MARX, Karl. O Capital. Crítica da economia política. 2ª ed. Coordenação e revisão de Paul Singer. Trad. de Regis Barbosa e Flávio R. Kothe. São Paulo: Nova Cultural, 1983/1985, Coleção: Os Economistas, Livros 1 a 3 em 5 tomos.

MARX, Karl. O Capital. Crítica da economia política. Livro I: o processo de produção do capital. Trad. de Rubens Enderle. 2. ed. São Paulo: Boitempo, 2017.

MARX, Karl. Resultate des unmittelbaren Produktionsprozesses. Das Kapital. I. Buch. Der Produktionsprozess des Kapitals. VI. Kapitel. Frankfurt: Verlag Neue Kritik, 1969.

MARX, Karl; ENGELS, Friedrich. Werke. Berlin: Dietz Verlag, 1956ss, 45v.

MIGEOTTE, Léopold. Os filósofos gregos e o trabalho na antiguidade. In: MERCURE, D.; SPURK, J. O trabalho na história do pensamento ocidental. Trad. de P.C. R. Reuillard e S. G. Taborda. Petrópolis: Vozes, 2005, p. 17-33.

NAPOLEONI, Cláudio. Lições sobre o capítulo VI (inédito) de Marx. Trad. de Carlos N. Coutinho. São Paulo: Livraria Editora Ciências Humanas, 1981.

OLIVEIRA. Júlio Ferreira. Ethos e politeia. Os fundamentos da concepção marxiana da economia. São Leopoldo: Editora Unisinos, 2004

REALE, Giovanni. História da filosofia antiga. Trad. H. C. Lima Vaz e M. Perine. São Paulo: Loyola, 1994, v. V.

RICOEUR, Paul. História e Verdade. Trad. de F. A. Ribeiro. Rio de Janeiro: Forense, 1968.

ROSDOLSKY, Roman. Gênese e estrutura de O capital de Karl Marx. Trad. César Banjamin. Rio de Janeiro: EDUERJ: Contraponto, 2001.

SANTOS, José Henrique. Trabalho e riqueza na Fenomenologia do Espírito de Hegel. São Paulo: Loyola, 1993.

SPURK, Jan. A noção de trabalho em Karl Marx. In: MERCURE, D.; SPURK, J. O trabalho na história do pensamento ocidental. Trad. de P.C. R. Reuillard e S. G. Taborda. Petrópolis: Vozes, 2005, p. 189-211.

WEIL, Eric. Filosofia política. Trad. de Marcelo Perine. São Paulo: Loyola, 1990.

Endereço do Autor:

Av. Dr. Rubens Guimarães, 2.127

Bairro Planalto

31720-300 Belo Horizonte - MG

edilcgf@gmail.com 